\title{
Expression of MicroRNA-1 and MicroRNA-21 in Different Protocols of Ischemic Conditioning in an Isolated Rat Heart Model
}

\author{
Xin Duan Bingyang Ji Xiaohua Wang Jinping Liu Zhe Zheng Cun Long \\ Yue Tang Shengshou Hu \\ State Key Laboratory of Cardiovascular Disease, Fuwai Hospital, National Center for Cardiovascular Diseases, \\ Chinese Academy of Medical Sciences and Peking Union Medical College, Beijing, PR China
}

\section{Key Words}

Ischemia-reperfusion $\cdot$ Ischemic conditioning $\cdot$ Isolated rat heart $\cdot$ MicroRNA

\begin{abstract}
Background: 'Conditioning' [ischemic preconditioning (IPC), ischemic postconditioning (IPO) and remote ischemic preconditioning (RIPC)] the heart to render it more resistant to an episode of acute myocardial ischemia-reperfusion (I/R) injury is an endogenous cardioprotective strategy. There are several mechanisms proposed for 'conditioning', such as endogenous mediators or cytoprotective proteins. In recent reports, microRNAs (miRNAs) were involved in controlling the expression of myocardial ischemia-related genes. Some studies have demonstrated that cardiac miRNA- 1 and miRNA-21 were significantly increased by late IPC with an increase in their target proteins [endothelial nitric oxide synthase and heat shock protein 70 (HSP70)], but their expression levels in 'conditioning' strategies are currently unknown. Methods: In the current study, Langendorff-perfused Sprague-Dawley rat hearts were randomly assigned to one of four groups [control group (CON group, $n=12$ ), IPC group ( $n=12)$, IPO group $(n=12)$ and RIPC group $(n=12)]$. Cardiac function was digitalized and analyzed. The expression of miRNA-1 and miRNA-21 was detected by real-time
\end{abstract}

reverse transcription polymerase chain reaction. The expression of HSP70, programmed cell death protein 4 (PDCD4), $\mathrm{B}$-cell lymphoma/leukemia-2 (BCl-2) and $\mathrm{BCl}$-2-associated $\mathrm{X}$ protein (Bax) was detected by Western blot. Cardiac infarct size and myocardial apoptosis were determined using the 2,3,5-triphenyltetrazolium chloride assay and terminal deoxynucleotidyl transferase dUTP nick end labeling assay, respectively. Results: The results revealed that miRNA-1 (233 $\pm 45 \%)$ and miRNA-21 (356 $\pm 33 \%$ ) expression was up-regulated in the IPC group, but the expression of miRNA-1 was down-regulated in the RIPC (61 $\pm 16 \%)$ group and IPO group (61 $\pm 13 \%)$. The expression of PDCD4 [IPC (74 $\pm 11 \%)$, RIPC $(81 \pm 16 \%)$, IPO $(83 \pm 12 \%)]$, HSP70 [IPC (74 $\pm 5 \%)$, RIPC (81 $\pm 6 \%)$, IPO $(67 \pm 11 \%)]$ and Bax [IPC (27 $\pm 6 \%)$, RIPC (21 \pm $3 \%)$, IPO (27 $\pm 4 \%)]$ was down-regulated in the conditioning groups compared with the CON group [PDCD4 (130 $\pm 11 \%)$, HSP70 (121 $\pm 11 \%)$ and Bax (63 $\pm 8 \%)]$. In the conditioning hearts, infarct size [IPC (31.7 $\pm 4.1 \%), \operatorname{RIPC}(29.6 \pm 6.19 \%)$ and IPO (32.8 $\pm 4.71 \%)]$ and myocardial apoptosis [IPC (15.2 \pm 4.21\%), RIPC (17.2 $\pm 1.92 \%)$ and IPO (15.6 $\pm 4.04 \%)]$ were significantly decreased compared with the CON group (infarct size: $51.77 \pm 4.3 \%$, myocardial apoptosis: $32.8 \pm 3.96 \%$ ). Conclusion: We concluded that miRNA-1 and miRNA-21 ex-

\section{X.D., B.J. and X.W. contributed equally to this work.}

\section{KARGER}

Fax +4161306 1234

E-Mail karger@karger.ch

www.karger.com (c) 2012 S. Karger AG, Basel

$0008-6312 / 12 / 1221-0036 \$ 38.00 / 0$

Accessible online at:

www.karger.com/crd
Assoc. Prof. Bingyang Ji, MD, State Key Laboratory of Cardiovascular Disease Fuwai Hospital, National Center for Cardiovascular Diseases Chinese Academy of Medical Sciences and Peking Union Medical College 167 Bei li shi Road, Fuwai Da Jie, Xi Cheng District, Beijing 100037 (PR China) Tel. +8610 8839 8285, E-Mail dr.ji.cpb@gmail.com 
pression differed in IPC, RIPC and IPO groups, and their target proteins were not inversely correlated with the miRNAs in all the conditioning groups, which revealed that the miRNAs were regulated but complicated by the different conditioning protocols.

Copyright $\odot 2012$ S. Karger AG, Basel

\section{Introduction}

'Conditioning' the heart to render it more resistant to an episode of acute myocardial ischemia/reperfusion (I/R) injury is an endogenous cardioprotective strategy which can be readily applied to the clinical setting of cardiac surgery to reduce myocardial injury and preserve left ventricular function [1]. There are three protocols: ischemic preconditioning (IPC), ischemic postconditioning and remote ischemic preconditioning, respectively. IPC, described as brief and repeated episodes of I/ $\mathrm{R} \mathrm{im-}$ mediately before a period of sustained ischemia, was first discovered by Murry et al. [2] in 1986. Vinten-Johansen's laboratory [3] first noted a phenomenon named ischemic postconditioning (IPO) that was described as brief and repeated episodes of ischemic reperfusion immediately after a period of sustained ischemia, producing less myocardial injury. In 1993, Przyklenk et al. [4] found the intriguing phenomenon that short episodes of myocardial ischemia and reperfusion applied to the left anterior descending coronary territory were able to reduce the size of a myocardial infarct generated in the circumflex coronary artery territory - a phenomenon which they termed 'regional ischemic preconditioning'. This concept of intramyocardial preconditioning was later extended to 'remote ischemic preconditioning' (RIPC), with the exciting finding that the preconditioning protocol could be applied to organs and tissue distant or remote from the heart, such as the kidney or limbs [5-7].

MicroRNAs (miRNAs) are endogenous 20-23-nucleotide (nt) small noncoding RNAs that negatively regulate gene expression in various eukaryotic organisms. The miRNA activity is involved in the control of a wide range of biological functions and processes, such as development, differentiation, metabolism, growth, proliferation and apoptosis $[8,9]$. In a study by Yin et al. [10], cardiac miRNA-1, miRNA-21 and miRNA-24 were significantly increased by late IPC. In their recent study, the IPCmiRNA treatment caused an increase in endothelial nitric oxide synthase (eNOS) and heat shock protein 70 (HSP70) versus control. They also demonstrated that miRNAs played an important role in the protection against myocardial I/R injury. Cheng et al. [11] demonstrated that IPC-regulated miRNA-21 protected the heart against I/R injury via anti-apoptosis through its target programmed cell death 4 (PDCD4).

In the present study, the expression of miRNA-1 and miRNA-21 and their target proteins HSP70 and PDCD4 were studied after three conditioning protocols in an isolated rat heart I/R model, and the proteins of B-cell lymphoma/leukemia-2 (Bcl-2) and Bcl-2-associated X (Bax), infarct size and myocardial apoptosis were assessed.

\section{Methods}

\section{Surgical Procedure}

Male Sprague-Dawley rats (weighing 300-350 g, $\mathrm{n}=40$ ) were used and anesthetized with pentobarbital ( $50 \mathrm{mg} / \mathrm{kg}$ i.p.). Heparin $(1,000 \mathrm{IU} / \mathrm{kg})$ was injected into the femoral vein. Hearts were rapidly removed and placed in ice-cold buffer, the aorta was cannulated and hearts were perfused in Langendorff perfusion apparatus mode using Krebs-Henseleit bicarbonate buffer (in mmol/l: glucose 11.0, $\mathrm{NaCl} 118.5, \mathrm{KCl} 4.75, \mathrm{MgSO}_{4} 1.19, \mathrm{KH}_{2} \mathrm{PO}_{4} 1.18$, $\mathrm{NaHCO}_{3} 25.0$ and $\mathrm{CaCl}_{2}$ 1.4) at $\mathrm{pH}$ 7.4. The buffer was bubbled with $95 \% \mathrm{O}_{2} / 5 \% \mathrm{CO}_{2}$ at $37^{\circ} \mathrm{C}$ and perfusion was performed under a hydrostatic pressure of $100 \mathrm{~cm} \mathrm{H}_{2} \mathrm{O}$. The experimental procedures conformed to the Guide for the Care and Use of Laboratory Animals published by the United States National Institutes of Health (NIH Publication No. 85-23, revised 1996) and were approved by the Research Commission on Ethics of the Fuwai Hospital.

\section{Experimental Protocol}

The hearts were randomly assigned to one of the four groups. Control hearts (CON, $\mathrm{n}=12$ ) were perfused for $20 \mathrm{~min}$ for stabilization followed by $30 \mathrm{~min}$ of global ischemia at $37^{\circ} \mathrm{C}$ and $60 \mathrm{~min}$ of reperfusion. The IPC hearts $(n=12)$ were achieved via two cycles of 2-min occlusion/2-min reperfusion of the aortic root during stabilization. RIPC hearts (RIPC, $\mathrm{n}=12$ ) were subjected to three cycles of 5-min occlusion and 5-min reperfusion of the bilateral femoral artery during induction of anesthesia. The lower-limb ischemia has been verified by means of pulse oxymetry modified for application in the rats. IPO hearts (IPO, $n=12$ ) were treated with 12 cycles of 5 -second occlusion and 5 -second reperfusion of the aortic root at the beginning of reperfusion (fig. 1).

\section{Cardiac Functional Measurements}

Isovolumetric measurement of left ventricular performance was made with a water-filled balloon connected to a pressure transducer (AD Instruments, Colorado Springs, Colo., USA) and inserted into the left ventricle across the mitral valve. The volume of the water-filled balloon was adjusted to an end-diastolic pressure $<10 \mathrm{~mm} \mathrm{Hg}$ and kept constant throughout the entire experiment. Left ventricular performance was assessed with heart rate, left ventricular developed pressure (LVDP) and maximum positive $\left(+\mathrm{dP} / \mathrm{dt}_{\max }\right)$ and negative derivative of left ventricular pressure $\left(-\mathrm{dP} / \mathrm{dt}_{\max }\right)$. Analog data (heart rate, LVDP and $\left.\pm \mathrm{dP} / \mathrm{dt}_{\max }\right)$ were digitalized and analyzed (Chart IV; AD Instruments). Hemodynamic data were compared at 10-, 20-, 30- and 60-min time points during reperfusion in all four groups. 


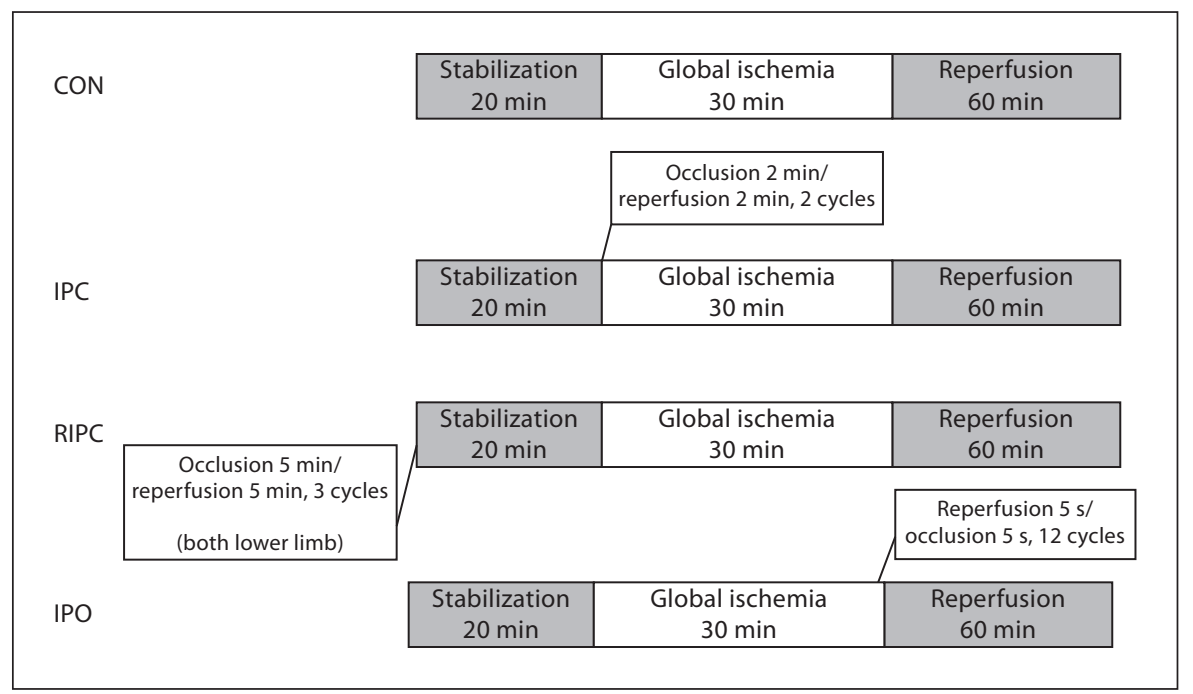

Fig. 1. The schematic of the protocols.

\section{Detection of miRNA-1 and miRNA-21 by Real-Time RT-PCR} Assay

The total miRNAs were extracted from the hearts of different groups after 60 min of reperfusion, using an mirVana ${ }^{\mathrm{TM}}$ miRNA isolation kit (Ambion, Austin, Tex., USA). The protocol was carried out according to the manufacturer's instructions. The total RNA was used to detect mature miRNA-1 and miRNA-21 expression with TaqMan ${ }^{\circledR}$ miRNA assays (Ambion). In brief, the realtime miRNA assay has two steps: stem-loop RT reaction and realtime PCR detection. Stem-loop RT primers bind to the $3^{\prime}$-end of miRNA molecules and are transcribed with reverse transcriptase. RT product is quantified using real-time PCR that includes miRNA-specific forward primer, reverse primer and carboxyfluorescein (FAM) dye-labeled reporter probes. To normalized RNA content, the U6 snRNA was the internal control. The relative miRNA-1 and miRNA-21 expression values in each group were calculated by the mathematical delta-delta method. For each group, reactions were run four times, respectively.

\section{Western Blot Analysis}

Total proteins were extracted from the left ventricle. The samples were placed in RIPA buffer (Beyotime Inst. Biotech, Peking, China), homogenized, incubated on ice for $20 \mathrm{~min}$ and then centrifuged at $12,000 \mathrm{~g}$ for $20 \mathrm{~min}$. Equal amounts of protein were subjected to SDS-PAGE. A standard Western blot analysis was conducted using PDCD4 antibody (Cell Signaling, Danvers, Mass., USA), HSP70, Bcl-2 and Bax antibody (Santa Cruz Biotechnology, Santa Cruz, Calif., USA). GAPDH antibody (Santa Cruz Biotechnology) was used as the loading control.

\section{Measurement of Myocardial Infarct Size}

Infarct size was verified using 1\% 2,3,5-triphenyltetrazolium chloride (TTC) staining after $60 \mathrm{~min}$ of reperfusion $(\mathrm{n}=5$ for each experimental group). The hearts were frozen at $-20^{\circ} \mathrm{C}$ for $20 \mathrm{~min}$ and cut into 2 -mm-thick slices from apex to base. The slices were incubated in $1 \%$ TTC at $37^{\circ} \mathrm{C}$ for $30 \mathrm{~min}$ to identify the non-infarcted and infarcted areas. Normal myocardium was then recognized as red staining by TTC, while necrotic tissue presented pale gray. Infarct size was identified by dividing the total necrotic area of the left ventricle by the total left ventricular slice area [11].

\section{Detection of Apoptosis}

After 60 min of reperfusion, left ventricular tissues were fixed in formalin for $24 \mathrm{~h}$, embedded in paraffin and sectioned. Apoptotic cells were identified by terminal deoxynucleotidyl transferase dUTP nick end labeling (TUNEL) using an apoptosis detection kit according to the manufacturer's protocol (Roche Diagnostics, Mannheim, Germany). TUNEL-positive myocytes and the number of total myocytes were counted with Leica Qwin plus V3 software and expressed as the number of TUNEL-positive cells per total nuclei, respectively.

\section{Statistics Analysis}

All data were expressed as means \pm SEM except for hemodynamic parameters (means $\pm \mathrm{SD}$ ). Hemodynamic data were analyzed with two-way ANOVA followed by Tukey post hoc tests. For the other data, the Tukey test was used for multiple post hoc comparisons. $\mathrm{p}<0.05$ (two-tailed) was considered statistically significant. All statistical analysis was performed with SPSS 13.0 software (SPSS, Chicago, Ill., USA).

\section{Results}

\section{Hemodynamic Analysis}

$\mathrm{LVDP}, \pm \mathrm{dP} / \mathrm{dt}_{\max }$, heart rate and coronary artery flow were recorded. At baseline, there were no differences among groups. During reperfusion, LVDP and $\pm \mathrm{dp} /$ $\mathrm{dt}_{\max }$ were significantly better preserved in the IPO group than the CON group at 10 min of reperfusion. $+\mathrm{dp} / \mathrm{dt}_{\max }$ in the RIPC group was significantly better preserved compared with the $\mathrm{CON}$ group at $10 \mathrm{~min}$ of 
Table 1. Cardiac function parameters

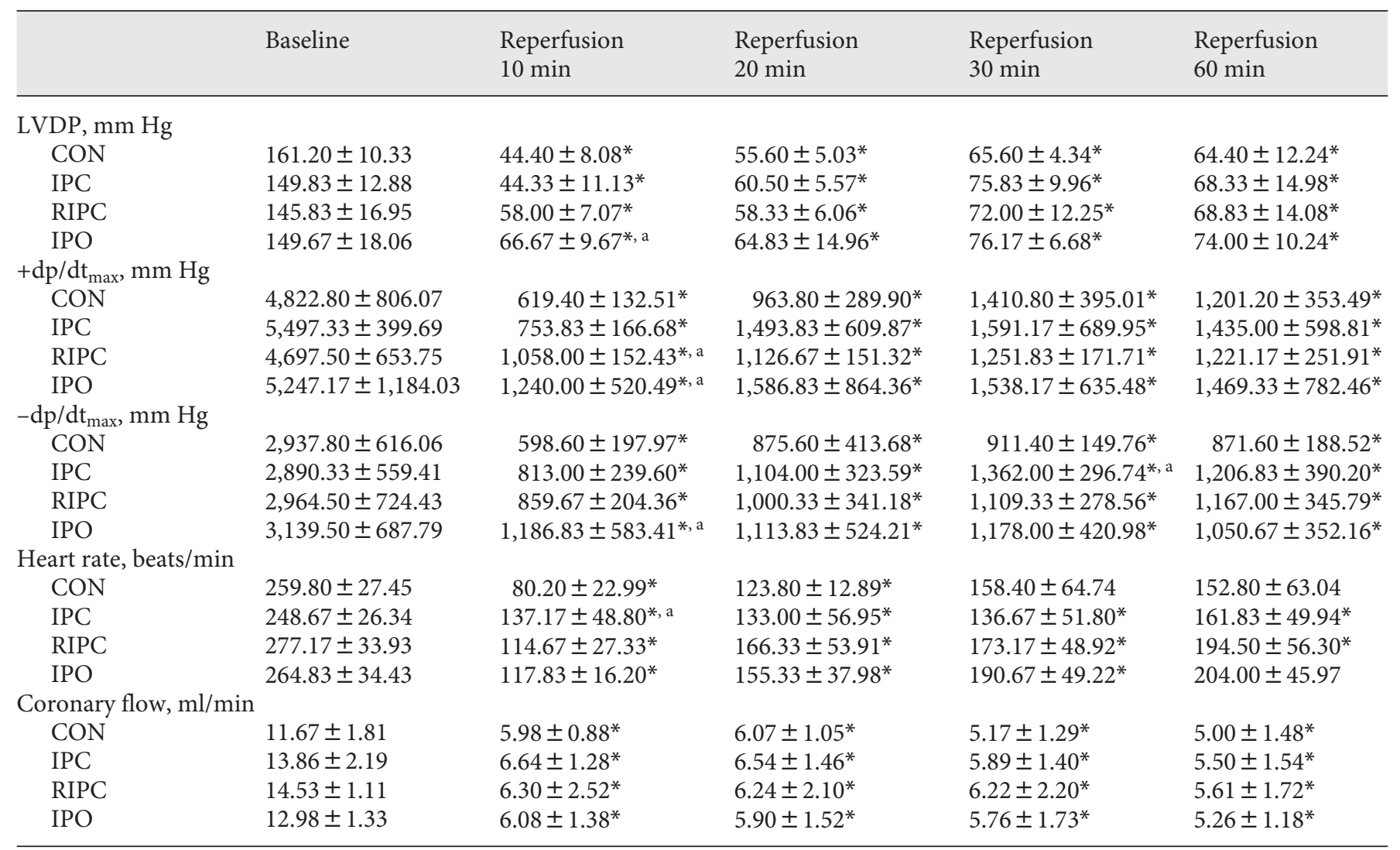

Data are presented as means $\pm \mathrm{SD} .{ }^{*} \mathrm{p}<0.05$ vs. baseline of the same group; ${ }^{\mathrm{a}} \mathrm{p}<0.05 \mathrm{vs}$. CON group at the same time.

reperfusion. In the IPC group, $-\mathrm{dp} / \mathrm{dt}_{\max }$ was significantly better than in the CON group at 30 min of reperfusion. Heart rate in the IPC group was better preserved than in the CON group at $10 \mathrm{~min}$ of reperfusion. Coronary artery flow was decreased at reperfusion in all groups compared with baseline, but there were no significant differences in the IPC, RIPC and IPO groups compared with the CON group. All data are summarized in table 1.

\section{Changes in miRNA-1 and miRNA-21 Expression}

The IPC protocol caused a significant increase in miRNA-1 (233 $\pm 45 \%)$ and miRNA-21 (356 $\pm 33 \%)$ compared with the CON group, but the expression of miRNA-1 was significantly decreased in the RIPC (61 \pm $16 \%)$ and IPO (61 $\pm 13 \%)$ groups compared with the CON group. There was no statistical significance in the expression of miRNA-21 in the RIPC $(68 \pm 23 \%)$ and IPO $(68 \pm 11 \%)$ groups compared with the CON group (fig. 2).

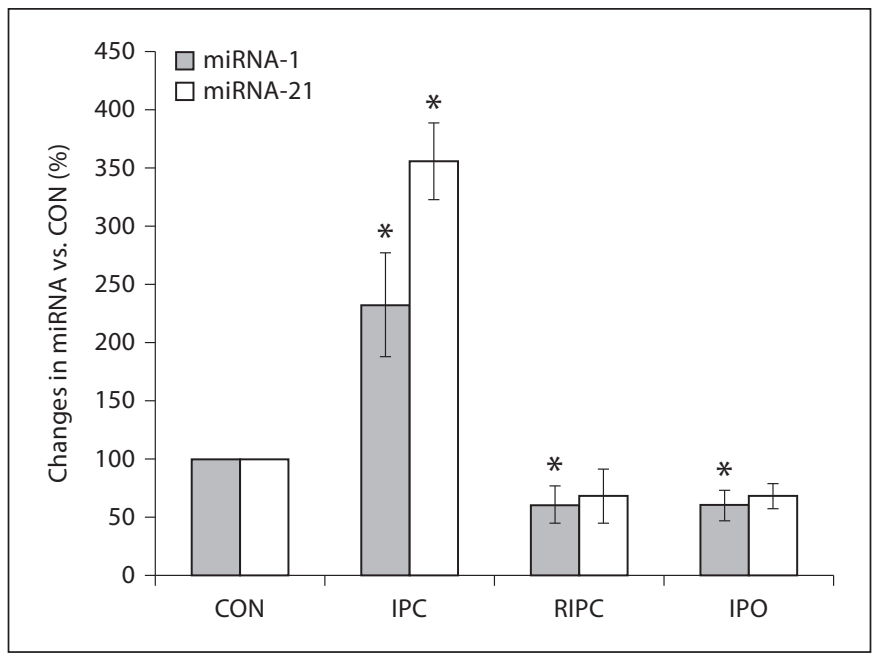

Fig. 2. miRNA-1 and miRNA-21 expression. Bar diagram shows average normalized changes in miRNA-1 and miRNA-21 in the IPC, RIPC and IPO groups compared with the CON group. ${ }^{*} \mathrm{p}<$ 0.05 vs. CON. 

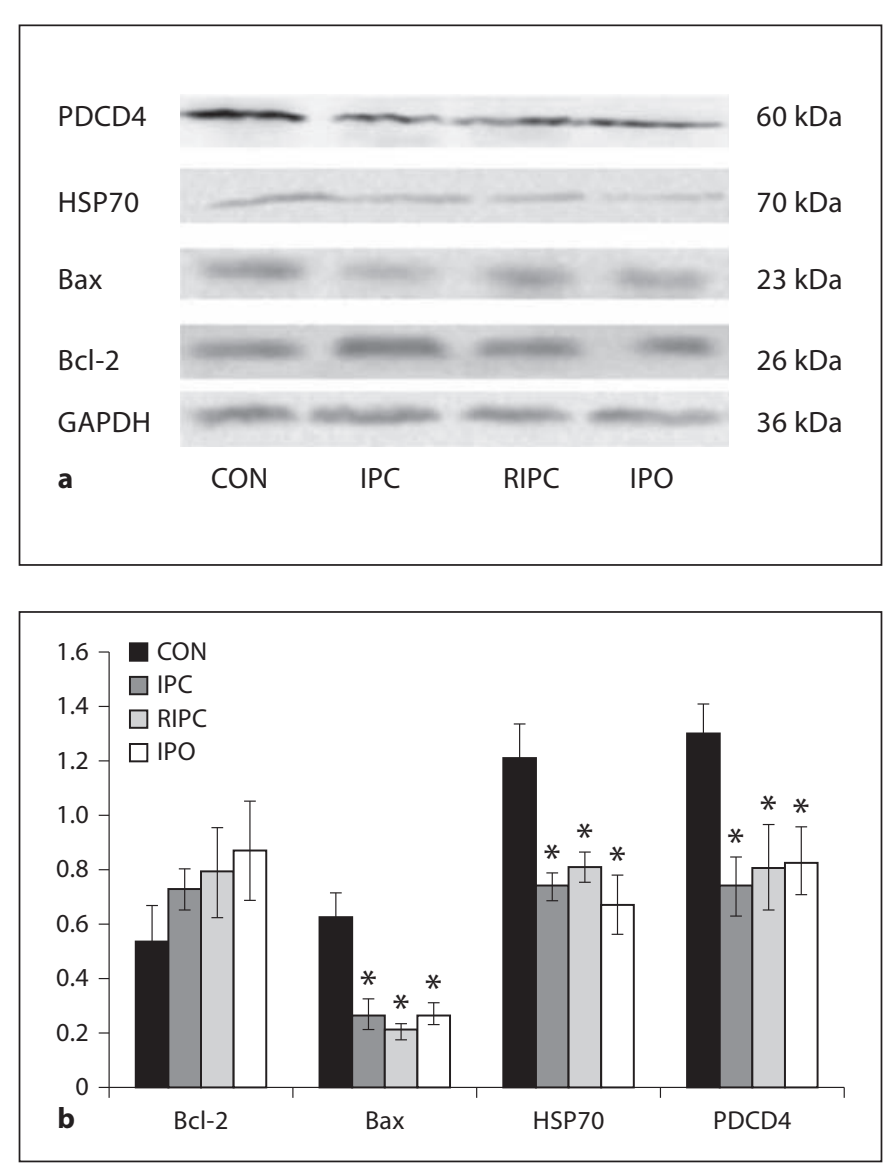

Fig. 3. a PDCD4, HSP70, Bcl-2 and Bax protein expression determined by Western blotting $(\mathrm{n}=3)$. $\mathbf{b}$ The densities of PDCD4, HSP70, Bcl-2 and Bax protein normalized against GAPDH expression. ${ }^{*} \mathrm{p}<0.05$ vs. the corresponding CON group.

\section{Change in Related Protein Expression}

Western blotting confirmed a significant decrease in HSP70 and PDCD4 in the 'conditioning' groups [HSP70: IPC (74 $\pm 5 \%)$, RIPC $(81 \pm 6 \%)$ and IPO (67 $\pm 11 \%)$, and PDCD4: IPC (74 $\pm 11 \%)$, RIPC (81 $\pm 16 \%)$ and IPO (83 $\pm 12 \%)$ ] compared to the CON group [HSP70 (121 \pm $12 \%)$ and PDCD4 (130 $\pm 11 \%)]$ after $60 \mathrm{~min}$ of reperfusion. Bax protein was significantly decreased in the 'conditioning' groups [IPC (27 $\pm 6 \%)$, RIPC $(21 \pm 3 \%)$ and IPO $(27 \pm 4 \%)$ ] compared to the CON group (63 $\pm 8 \%)$. The expression of $\mathrm{Bcl}-2$ protein in the 'conditioning' groups [IPC (73 $\pm 8 \%)$, RIPC (79 $\pm 16 \%)$ and IPO (87 \pm $18 \%)]$ was not statistically significantly different compared to the CON group (54 $\pm 12 \%$; fig. 3 ).
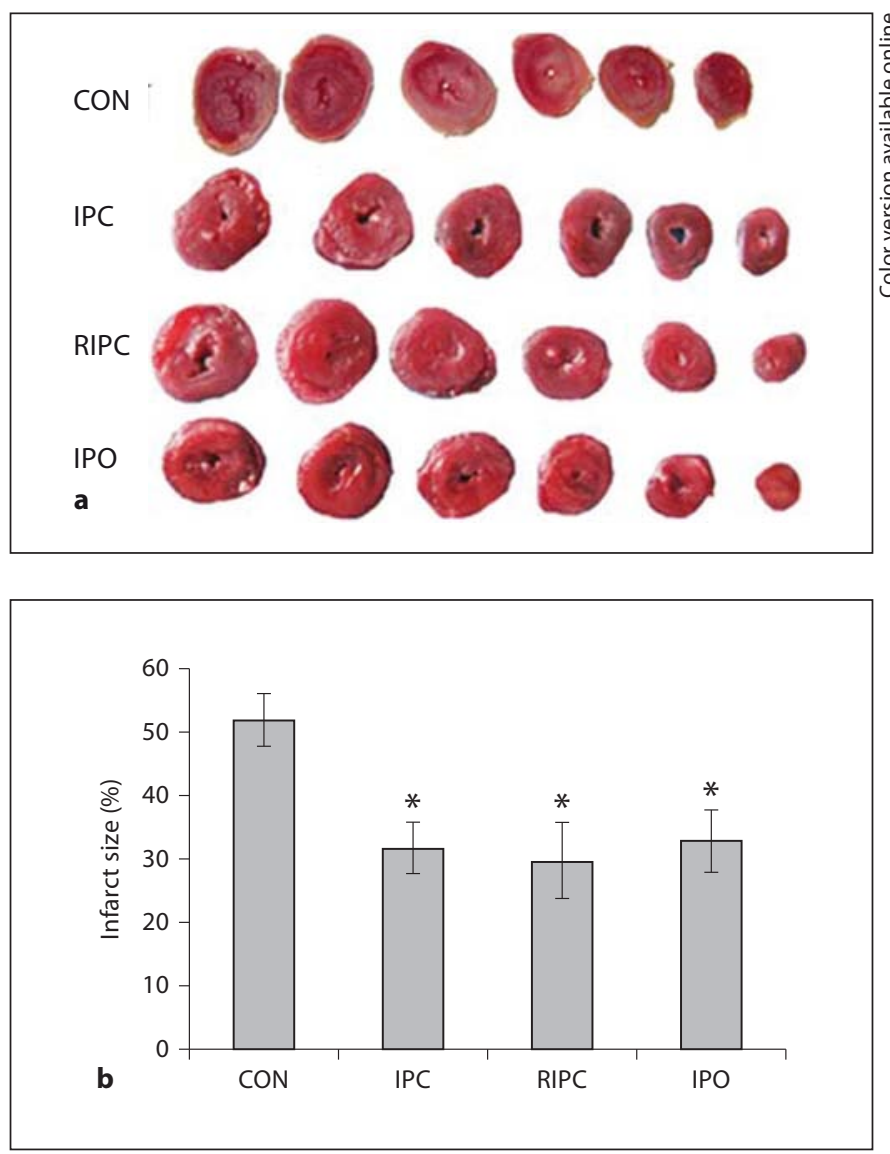

Fig. 4. Infarct size assessed by TTC staining. a Representative TTC-stained heart slices in the four groups. $\mathbf{b}$ Infarct size was identified by dividing the total necrotic area of the left ventricle by the total left ventricular slice area. ${ }^{*} \mathrm{p}<0.05 \mathrm{vs}$. the CON group.

\section{Infarct Size Assessment}

Myocardial infarct size was determined by TTC assay. The results showed that myocardial infarct size was significantly decreased in the IPC (31.7 $\pm 4.1 \%)$, RIPC (29.6 $\pm 6.19 \%)$ and IPO $(32.8 \pm 4.71 \%)$ groups compared with CON (51.77 $\pm 4.3 \%)$. Representative TTC-stained heart slices from these four groups are shown in figure 4.

\section{Effect of the 'Conditioning' Protocol on Myocardial Apoptosis}

With in situ end-labeling of tissue sections, myocardial specimens were examined for final stages of apoptosis. Positive staining was observed in the CON, IPC, RIPC and IPO groups $(32.8 \pm 3.96$ vs. $15.2 \pm 4.21$ vs. 17.2 \pm 1.92 vs. $15.6 \pm 4.04 \%)$, respectively. The apoptotic rate was significantly lower in the 'conditioning' groups than the CON group (fig. 5). 


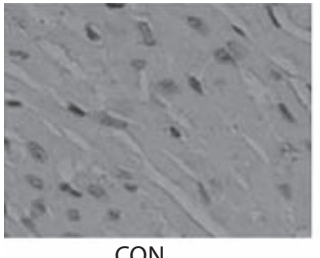

CON

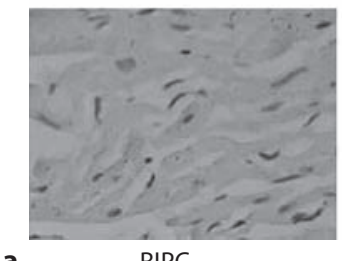

a

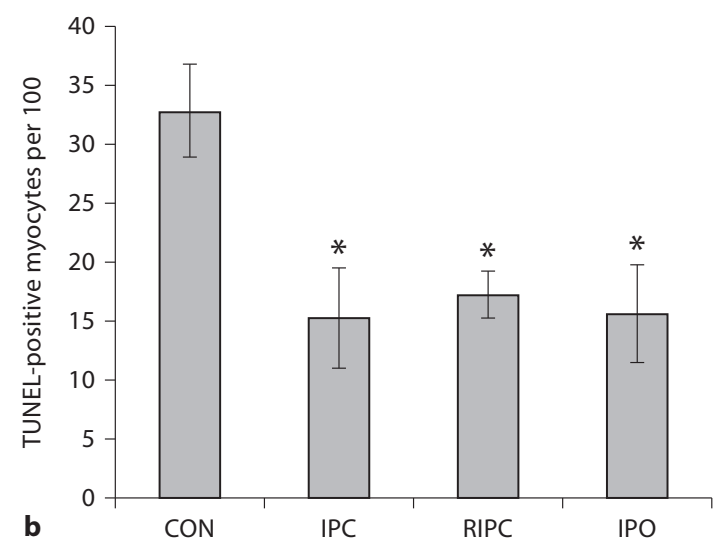

Fig. 5. The apoptotic myocardium by TUNEL assay. a Representative examples of apoptotic myocardium in the four groups. b Quantitative analysis of apoptotic myocardium in the four groups. ${ }^{*} \mathrm{p}<0.05$ vs. the CON group.

\section{Discussion}

In the current study, we evaluated changes in miRNA-1 and miRNA-21 expression under different 'conditioning' protocols of the Langendorff model. The results revealed that miRNA-1 and miRNA-21 expression was up-regulated in the IPC group but down-regulated in the RIPC and IPO groups. PDCD4, Bax and HSP70 expression was down-regulated, but Bcl-2 expression was up-regulated in 'conditioning' hearts. The results also demonstrated that infarct size and myocardial apoptosis were decreased in the 'conditioning' groups. The hearts exposed to RIPC were conditioned in vivo, while the other 'conditioning' groups were conditioned in vitro. Lim et al. [12] had demonstrated that the mechanism of cardioprotection was attributable to both a neural and humoral pathway in RIPC.
Kristiansen et al. [13] demonstrated that RIPC applied in vivo could exert cardioprotection upon the heart after explantation from the body. Some studies had demonstrated the IPC and IPO protocols could exert cardioprotection in vitro $[14,15]$. Therefore, we designed the protocols using the Langendorff model.

'Conditioning' the heart to tolerate the effects of acute I/R injury can be initiated through the application of several different endogenous cardioprotective strategies. Mechanisms proposed for 'conditioning', which either individually or collaboratively protect the heart against I/R injury, are the reperfusion injury salvage kinase pathway, including G-coupled receptors and protein kinase C, and synthesis of cytoprotective proteins, including eNOS, inducible nitric oxide synthase and HSP70 [16-18].

Recent studies revealed an important role for miRNAs and their target genes in regulating cardiac I/R injury [10, $11,19]$. miRNA-1 is specifically expressed in cardiac and skeletal muscles $[20,21]$. Xu et al. [19] found that increased miRNA-1 reduced the levels of its target HSP70 proteins without changing its transcription levels, which induced myocardial apoptosis. In the current study, the results revealed the level of miRNA-1 was inversely correlated with HSP70 expression in the IPC but not in the RIPC and IPO groups.

HSP70s have been demonstrated to be involved in the protection against I/R injury. They have been shown to inhibit the mitochondrial death pathway by preventing oligomerized Apaf-1 from recruiting pro-Casp9 [22, 23]. However, Hampton et al. [24] found HSP70 proteins did not play an important role in cardioprotection in the early IPC phase. The current study showed repression of HSP70 in the 'conditioning' groups at $60 \mathrm{~min}$ of reperfusion, which may be the reason for the inconsistency with the results of Yin et al. [10]. In a study by Yu et al. [25], the transcription and expression of HSP70 were also influenced by heat shock transcription factor and heat shock element, which may explain the relationship of miRNA-1 and HSP70 in the current study.

It has been shown that miRNA-21 and its target gene PDCD4 could significantly reduce infarct size and apoptosis after I/R injury [11]. In the current study, the level of miRNA-21 was significantly increased and the expression of PDCD4 was decreased in the IPC group, which was consistent with the study by Cheng et al. [11]. However, both the level of miRNA-21 and PDCD4 expression were decreased in the RIPC and IPO groups, which did not show an inverse correlation. In previous studies, expression and transcription of PDCD4 was influenced by other transcription factors [26]. 
$\mathrm{Bcl}-2$ is a central player in the genetic program of cardiomyocytes favoring survival by inhibiting cell death [27]. Many apoptosis-regulating mechanisms have an association with Bcl-2 in cardiomyocytes. Bax was one of the pro-apoptotic proteins in the mitochondrial death pathway. In the current study, the level of Bax was significantly decreased in the 'conditioning' groups compared with the control group, but the level of Bcl-2 was not significantly altered, which was correlated with the results of myocardial apoptosis in the current study.

Infarct size and apoptotic myocardium were all decreased in the 'conditioning' groups, which effectively confirmed the 'conditioning' protocols for cardioprotection. Schmitt et al. [28] demonstrated that myocardial apoptosis was evident early after I/R and correlated with declining cardiac contractility. Penna et al. [29] demonstrated that there was a high level of linear correlation between infarct size and end-diastolic left ventricular pressure. In the current study, the parameters of cardiac function revealed that cardiac systolic and diastolic function was better preserved in the IPO group, and that dia- stolic function in the IPC group and systolic function in the RIPC group were better preserved after reperfusion, which may be explained by inhibiting cell necrosis and apoptosis in the 'conditioning' group.

In the current study, miRNA-1 and miRNA-21 were differently expressed in the IPC, RIPC and IPO groups, which may indicate that the different miRNAs are regulated by different 'conditioning' protocols, and the cardioprotective proteins may be regulated by multiple miRNAs. In future studies, we aim to identify further miRNAs that possess cardioprotective properties using RIPC and IPO protocols and elucidate the mechanisms of 'conditioning' protocols. We hope to find a new cardioprotective way using miRNA intervention.

\section{Limitations}

We studied the expression of miRNA-1 and miRNA21 and their target proteins using different 'conditioning' protocols in an in vitro model. According to our results, other factors than miRNA-1 and miRNA-21 are responsible for the control of HSP70 and PDCD4 expression.

\section{References}

1 Hausenloy DJ, Yellon DM: The evolving story of 'conditioning' to protect against acute myocardial ischaemia-reperfusion injury. Heart 2007;93:649-651.

-2 Murry CE, Jennings RB, Reimer KA: Preconditioning with ischemia: a delay of lethal cell injury in ischemic myocardium. Circulation 1986;74:1124-1136.

3 Zhao ZQ, Corvera JS, Halkos ME, Kerendi F, Wang NP, Guyton RA, Vinten-Johansen J: Inhibition of myocardial injury by ischemic postconditioning during reperfusion: comparison with ischemic preconditioning. Am J Physiol Heart Circ Physiol 2003;285:H579_ H588.

4 Przyklenk K, Bauer B, Ovize M, Kloner RA, Whittaker P: Regional ischemic 'preconditioning' protects remote virgin myocardium from subsequent sustained coronary occlusion. Circulation 1993;87:893-899.

5 Gho BC, Schoemaker RG, van den Doel MA, Duncker DJ, Verdouw PD: Myocardial protection by brief ischemia in noncardiac tissue. Circulation 1996;94:2193-2200.

-6 Pell TJ, Baxter GF, Yellon DM, Drew GM: Renal ischemia preconditions myocardium: role of adenosine receptors and ATP-sensitive potassium channels. Am J Physiol 1998. 275:H1542-H1547.
7 Kharbanda RK, Mortensen UM, White PA, Kristiansen SB, Schmidt MR, Hoschtitzky JA, Vogel M, Sorensen K, Redington AN, MacAllister R: Transient limb ischemia induces remote ischemic preconditioning in vivo. Circulation 2002;106:2881-2883.

$\checkmark 8$ Bushati N, Cohen SM: MicroRNA functions. Annu Rev Cell Dev Biol 2007;23:175-205.

-9 Chang TC, Mendell JT: MicroRNAs in vertebrate physiology and human disease. Annu Rev Genomics Hum Genet 2007;8:215-239.

10 Yin C, Salloum FN, Kukreja RC: A novel role of microRNA in late preconditioning: upregulation of endothelial nitric oxide synthase and heat shock protein 70. Circ Res 2009;104: 572-575.

11 Cheng Y, Zhu P, Yang J, Liu X, Dong S, Wang $\mathrm{X}$, Chun B, Zhuang J, Zhang C: Ischaemic preconditioning-regulated miR-21 protects heart against ischaemia/reperfusion injury via anti-apoptosis through its target PDCD4. Cardiovasc Res 2010;87:431-439.

12 Lim SY, Yellon DM, Hausenloy DJ: The neural and humoral pathways in remote limb ischemic preconditioning. Basic Res Cardiol 2010;105:651-655.

13 Kristiansen SB, Henning O, Kharbanda RK, Nielsen-Kudsk JE, Schmidt MR, Redington AN, Nielsen TT, Botker HE: Remote preconditioning reduces ischemic injury in the explanted heart by a KATP channel-dependent mechanism. Am J Physiol Heart Circ Physiol 2005;288:H1252-H1256.
14 Ogino H, Smolenski RT, Zych M, Seymour AM, Yacoub MH: Influence of preconditioning on rat heart subjected to prolonged cardioplegic arrest. Ann Thorac Surg 1996;62: 469-474.

15 Penna C, Mancardi D, Tullio F, Pagliaro P: Postconditioning and intermittent bradykinin induced cardioprotection require cyclooxygenase activation and prostacyclin release during reperfusion. Basic Res Cardiol 2008;103:368-377.

16 Hausenloy DJ, Tsang A, Yellon DM: The reperfusion injury salvage kinase pathway: a common target for both ischemic preconditioning and postconditioning. Trends Cardiovasc Med 2005;15:69-75.

17 Wang Y, Xu H, Mizoguchi K, Oe M, Maeta $\mathrm{H}$ : Intestinal ischemia induces late preconditioning against myocardial infarction: a role for inducible nitric oxide synthase. Cardiovasc Res 2001;49:391-398.

18 Kuntscher MV, Kastell T, Altmann J, Menke H, Gebhard MM, Germann G: Acute remote ischemic preconditioning II: the role of nitric oxide. Microsurgery 2002;22:227-231.

$\checkmark 19$ Xu C, Lu Y, Pan Z, Chu W, Luo X, Lin H, Xiao J, Shan H, Wang Z, Yang B: The muscle-specific microRNAs miR-1 and miR-133 produce opposing effects on apoptosis by targeting HSP60, HSP70 and caspase-9 in cardiomyocytes. J Cell Sci 2007;120:30453052. 
20 Kwon C, Han Z, Olson EN, Srivastava D: MicroRNA1 influences cardiac differentiation in Drosophila and regulates Notch signaling. Proc Natl Acad Sci USA 2005; 102:1898618991.

21 Chen JF, Mandel EM, Thomson JM, Wu Q, Callis TE, Hammond SM, Conlon FL, Wang DZ: The role of microRNA-1 and microRNA-133 in skeletal muscle proliferation and differentiation. Nat Genet 2006;38:228233.

-22 Heusch G, Boengler K, Schulz R: Cardioprotection: nitric oxide, protein kinases, and mitochondria. Circulation 2008;118:19151919.

23 Latchman DS: Heat shock proteins and cardiac protection. Cardiovasc Res 2001;51: 637-646.
24 Hampton CR, Shimamoto A, Rothnie CL, Griscavage-Ennis J, Chong A, Dix DJ, Verrier ED, Pohlman TH: HSP70.1 and -70.3 are required for late-phase protection induced by ischemic preconditioning of mouse hearts. Am J Physiol Heart Circ Physiol 2003; 285:H866-H874.

25 Yu HP, Shimizu T, Choudhry MA, Hsieh YC, Suzuki T, Bland KI, Chaudry IH: Mechanism of cardioprotection following trauma-hemorrhagic shock by a selective estrogen receptor-beta agonist: up-regulation of cardiac heat shock factor-1 and heat shock proteins. J Mol Cell Cardiol 2006;40:185-194.

26 Schlichter U, Burk O, Worpenberg S, Klempnauer KH: The chicken Pdcd4 gene is regulated by v-Myb. Oncogene 2001;20:231-239.
7 Wang G, Liem DA, Vondriska TM, Honda HM, Korge P, Pantaleon DM, Qiao X, Wang $Y$, Weiss JN, Ping P: Nitric oxide donors protect murine myocardium against infarction via modulation of mitochondrial permeability transition. Am J Physiol Heart Circ Physiol 2005;288:H1290-H1295.

28 Schmitt JP, Schroder J, Schunkert H, Birnbaum DE, Aebert H: Role of apoptosis in myocardial stunning after open heart surgery. Ann Thorac Surg 2002;73:1229-1235.

29 Penna C, Tullio F, Merlino A, Moro F, Raimondo S, Rastaldo R, Perrelli MG, Mancardi D, Pagliaro P: Postconditioning cardioprotection against infarct size and post-ischemic systolic dysfunction is influenced by gender. Basic Res Cardiol 2009;104:390-402. 